\title{
Longitudinal study of the learning styles evolution in Engineering degrees
}

\author{
Miguel A. Molina-Cabello, Karl Thurnhofer-Hemsi, Enrique Domínguez, \\ Ezequiel López-Rubio, and Esteban J. Palomo \\ 1 Department of Computer Languages and Computer Science, University of Malaga \\ Bulevar Louis Pasteur, 35. 29071 Málaga. Spain \\ 2 Instituto de Investigación Biomédica de Málaga - IBIMA, Spain \\ \{miguelangel, karlkhader, enriqued, ezeqlr, ejpalomo\}@lcc.uma.es
}

\begin{abstract}
A learning style describes what are the predominant skills for learning tasks. In the context of university education, knowing the learning styles of the students constitutes a great opportunity to improve both teaching and evaluation. By using the Honey-Alonso Learning Styles Questionnaire (CHAEA), in this work, we carried out a longitudinal study of the correlation between marks and the results of the survey. The 2018/2019, 2019/2020, and 2020/2021 academic years in two different courses from Computer Sciences engineering degrees were studied. The results were analyzed in order to evaluate the impact of the adaptation to digital lessons during the last year.
\end{abstract}

Keywords: Learning styles, grades, web-based education, higher education

\section{Introduction}

Education researchers have been searching for the factors that affect student evaluation. One of these factors is represented by the student learning styles, which refer to individual approaches or preferences used while receiving, processing, organizing, and using information [3]. They are drawn from the speculations based on behavior observation and personal statements through a variety of learning style inventories $[12,13]$. Thus, the Learning Style Questionnaire (LSQ) designed by Honey and Mumford [4] was derived from the Learning Style Inventory (LSI) [6] and it was later adopted by Alonso, Gallego, and Honey to the Spanish educational context [1].

Studying the learning styles involves paying attention to the characteristics, cognitive, affective, and physiological behaviors that different students can present and have a direct impact on the acquisition and learning process. This way, learning styles allow us to "conclude" how people act, and are useful for classifying and analyzing behaviors. With that in mind, different learning methodologies take into account these specific features to design the student learning process such as adaptive learning which focuses on maximizing the learning 
performance of each student by deploying learning resources adapted to the student's characteristics [7].

The Honey-Alonso Learning Styles Questionnaire (CHAEA) is a tool designed for identifying four learning styles (activist, reflector, theorist, and pragmatist) that can be present in each student to a different degree. Activists learn by doing, while reflectors learn by observing and thinking about what is happening. Regarding theorists, they need models, concepts and facts to learn. Respecting pragmatists, they are practical people. These modalities are not exclusive so that a person can present several ones. The questionnaire consists of 80 assertions divided into four sections of 20 items corresponding to the four different learning styles. They can be utilized in any educational area at any age. Most of the research papers are focused on applying the CHAEA questionnaire to university students from many different areas, namely, engineering, sanitary, humanities, etc. [2].

The CHAEA questionnaire has been widely employed over the years. The identification of the differences between the results in the study of the learning styles preferences of teachers and postgraduate students was addressed in [11], whereas in [5] the CHAEA questionnaire, together with the ACRA scale was used as potential tools to identify the psychoeducational features of students starting a university degree. Also, a recommendation system of educational strategies based on rules according to the CHAEA questionnaire was proposed in [8]. More recently, the CHAEA questionnaire was used in [9] with engineering university students to analyze development, performance, and gender.

In this paper, a longitudinal study of the learning styles evolution by means of the CHAEA questionnaire is proposed. Concretely, the CHAEA questionnaire was used in two courses from two different computer engineering degrees from the University of Malaga during 3 academic years. Therefore, the information gathered from the CHAEA questionnaire together with the student's marks are not only used to analyze the student learning styles but also the student adaptation to the online lessons due to the pandemic. This way, this study aims to determine if the students' learning styles of a subject and their marks in the different academic years are related. If so, this would allow us in subsequent years to design the course programming adapted to the detected learning styles and thus favour the students' learning process.

The rest of this paper is organized as follows. The academic context is shown in Section 2. In Section 3 the evaluation methodologies are presented. The project results are given in Section 4. Finally, Section 5 is devoted to conclusions.

\section{Academic Context}

The University of Malaga offers a wide range of degrees from every branch of knowledge, having 59 bachelor degrees, 53 master's degrees, and 35,000 students. Therefore, diversity is not only present speaking of degrees, but also of academic years and courses. For example, whereas an engineering degree can have students with a more practical profile, students will be more thoughtful in a communica- 
Table 1. Summary of number of enrolled students (Attd.) and the participants in the survey (Resp.) among the considered subjects.

\begin{tabular}{|c|c|c|c|c|c|c|}
\hline Subject & Degree & Course & Year & Attd. & Resp. & Rate \\
\hline \multirow{3}{*}{ TALF } & \multirow{3}{*}{ Comp. Science / Comp. Engineering } & \multirow{3}{*}{ 2nd } & $18 / 19$ & 138 & 55 & $39.86 \%$ \\
\hline & & & $19 / 20$ & 135 & 58 & $42.96 \%$ \\
\hline & & & $20 / 21$ & 150 & 39 & $26.00 \%$ \\
\hline \multirow{3}{*}{ TCIS } & \multirow{3}{*}{ Software Engineering } & \multirow{3}{*}{$3 r d$} & $18 / 19$ & 60 & 28 & $46.67 \%$ \\
\hline & & & $19 / 20$ & 70 & 42 & $60.00 \%$ \\
\hline & & & $20 / 21$ & 66 & 36 & $54.54 \%$ \\
\hline
\end{tabular}

tions degree. However, even in the same degree, students from different academic years can undergo different profile variations.

In this work, the information from three courses has been gathered, trying to cover a wide variety. This information is given in Table 1 . Courses from the first years of a degree have been avoided since there can be an important bias in the results since many students do not be clear about which degree want to study. Likewise, a sample formed by three different courses from different degrees that belong to the Computer Sciences engineering branch has been used in order to perform a complete analysis.

On the other hand, it would be advisable to contextualize the assessment methodologies of each analyzed course briefly. Automata Theory and Formal Languages (TALF) course is one of the most theoretical courses from the computer science point of view and also has a sizeable mathematical content. The TALF assessment consists of 4 independent mid-term exams that can remove contents from the final exam. The mid-term exams have an only test about the course contents with penalization in failed questions. Students must pass all the mid-term exams to pass this course. Regarding the Computational Techniques in Software Engineering (TCIS) course, its assessment is formed by 13 laboratory practices, two mid-term exams that can remove contents, and a final exam.

In Table 2, the average and standard deviation grades of the overall group is presented for each subject and year is shown. As it can be extracted, one of the subjects, TCIS, has outstanding qualifications since it was easy for the students. That is because its evaluation is based on practices without the need to pass a final exam. On the other hand, TALF is a complex theoretical subject that many students fail in it.

\section{Evaluation Methodologies}

There are several tools that allow to compute the learning styles of the students in an online way. In this work Moodle has been the selected software since our university uses it as learning management system [10]. This software provides many resources, the quiz module among them, which easily supports the management of a questionnaire. 
Table 2. Average mark and standard deviation by differentiating between those students who have responded to the CHAEA survey, those who have not responded to the survey and all students (who has responded and who not) for each subject and course.

\begin{tabular}{c|c|c|c|c}
\hline Subject & Surveyed & $\mathbf{1 8 / 1 9}$ & $\mathbf{1 9 / 2 0}$ & $\mathbf{2 0 / 2 1}$ \\
\hline \multirow{3}{*}{ TALF } & Yes & $6.35 \pm 2.30$ & $6.47 \pm 2.13$ & $6.26 \pm 1.88$ \\
& No & $4.82 \pm 2.75$ & $5.33 \pm 2.72$ & $5.39 \pm 2.31$ \\
& Total & $5.43 \pm 2.68$ & $5.82 \pm 2.54$ & $5.62 \pm 2.23$ \\
\hline \multirow{3}{*}{ TCIS } & Yes & $8.17 \pm 0.98$ & $8.03 \pm 1.39$ & $8.27 \pm 1.40$ \\
& No & $7.93 \pm 1.24$ & $8.23 \pm 1.27$ & $8.04 \pm 1.22$ \\
& Total & $8.04 \pm 1.13$ & $8.11 \pm 1.34$ & $8.17 \pm 1.32$ \\
\hline
\end{tabular}

At the beginning of the course, students are asked to fullfil the CHAEA questionnaire. This task is not mandatory, so that it is optional and it does not affect the final grade. Regarding the final evaluation, it is computed at the end of the course as usual.

It is known that the instructor has the possibility of selecting a simple grading or a complex one. In this work, with the objective of a clear explanation of the grading process, each student is graded with a numerical evaluation in the range between 0 and 10 .

\section{Project Results}

Next, the results of the surveys and the correlation with the marks are presented for each of the analyzed subjects.

First of all, in Table 1 is presented the respondents rate with respect to the total number of students of each subject, during the last three years. Due to several students do not finish the CHAEA survey, a student is considered that has completed the survey if that survey has at least the $75 \%$ of the questions of the survey. So that it is considered as completed if it has at least 60 responded questions (CHAEA survey has 80 questions). As it can be seen, there is not a clear tendency, although the greatest differences are in the subject TALF, where there are a large number of students. The online modality of the year 20/21 has not motivated the students to complete the survey more than the past years. The equality in the number of respondents will facilitate the extraction of conclusions of the evolution among years.

The average learning style profiles for each subject are presented in Figs. 1 and 2. The colors represent the results of each year. In TALF, there is a small but not very significant change in the type of learning style. In the first two years the students seemed to be more active and theorist, while the course 20/21 pushed their reflexive side. That is, since most of the lessons were carried out in an online mode, the students tend to analyze and observe more the explanations and exercises than trying to participate actively in the lessons. 


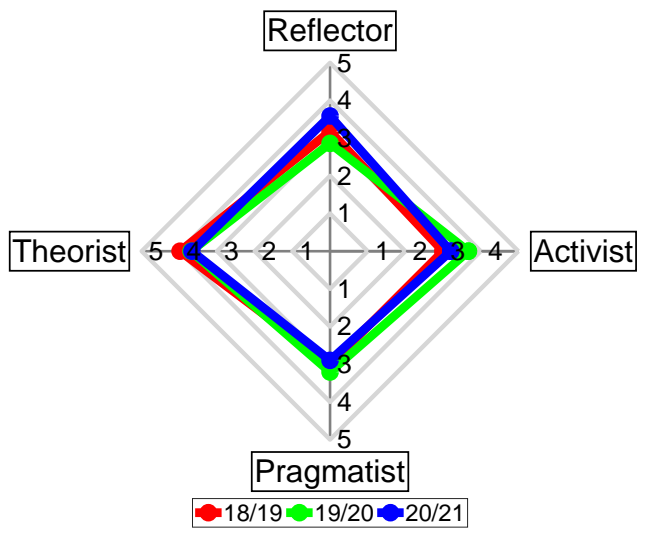

Fig. 1. Average learning style profile of the subject TALF.

In the case of TCIS, no differences were found. This behavior might be caused due to the different evaluation system. In this subject, several small practices are proposed to the students, and two mid-term exams facilitates the elimination of content. That is, the evaluation is continuous and it has not changed in the almost online year 20/21. However, the way the lessons were given in TALF have changed a bit and practice lessons have almost disappeared, provoking a small change in the learning style of the students.

In order to analyze the marks, Figs. 3 and 4 exhibit the whisker plots for subjects TALF and TCIS, respectively, where the maximum whisker length has been specified as 0.75 times the interquartile range. On one hand, in Fig. 3 it can be appreciated a difference in the marks obtained by those students who completed the survey and those who did not. Except for some outlying cases, the median value is almost 2 points lower and the spread in higher. In general, there is a great variety of marks within this set of students, which indicates that the subject is complex and needs special effort to pass it. The evolution along the years is negative, that is, the grades have got worse. The cause is unclear but it can be the decreasing level of mathematical fundamentals required for this subject.

On the other hand, TCIS presented better marks in Fig. 4, and the median and dispersion are very similar for any type of student. Nevertheless, again the students with less interest in the questionnaire are those who obtained lower marks, with the exception of the course 19/20. The overall grades are good (greater than 8) and there are few falling students.

In Table 2 the average marks can be compared. The tendency is very similar to the median represented in the whisker plots. The major discrepancies are found in TALF, where the mean values do not show a clear decrease. Even in the course $20 / 21$, it has increased slightly with respect to two years ago. The case of the TCIS subject is analogous. The unexpected result is the 8.23 points 


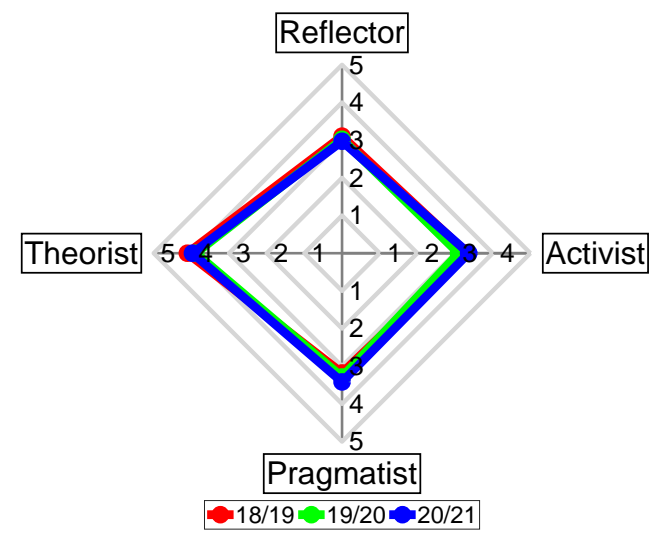

Fig. 2. Average learning style profile of the subject TCIS.

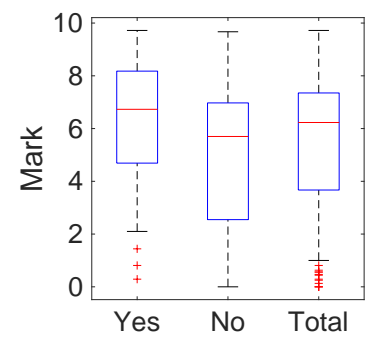

(a) $18 / 19$

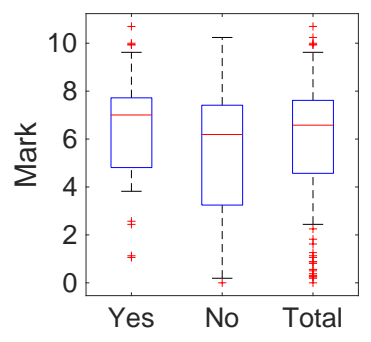

(b) $19 / 20$

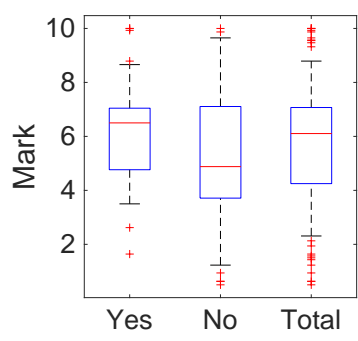

(c) $20 / 21$

Fig. 3. Whisker plot of marks, by differentiating between those students who have responded to the CHAEA survey, those who have not responded to the survey and all students (who have responded and who not) for subject TALF.

of the course $19 / 20$, which is higher for the students who did not complete the CHAEA survey. The standard deviation of both subjects goes accordingly with what was shown in the previous figures.

By last, the correlation of the CHAEA marks and the subject grades is analyzed in Figs. 5 and 6, using the information of the last course 20/21. A linear regression was computed, using as samples each of the students of the subject. $R^{2}$ (where the higher, the better) and MSE (the lower, the better) measures are also provided to compare better the relation between assessment mark (which is in the range 0 and 10) and CHAEA mark (range 0 and 20) of each learning style for each student of the studied subjects. In the case of TALF, the best fits are achieved for both the reflector and theorist learning styles, where the residual values are the lowest. Actually, the best CHAEA marks are obtained in these styles, which confirm that the students are more reflexive than past years. The 


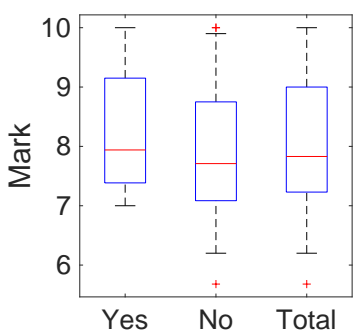

(a) $18 / 19$

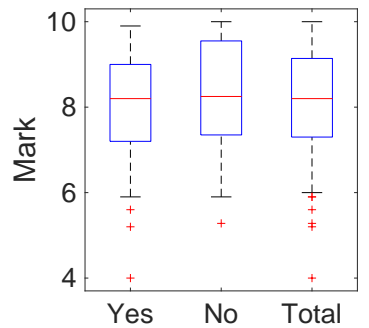

(b) $19 / 20$

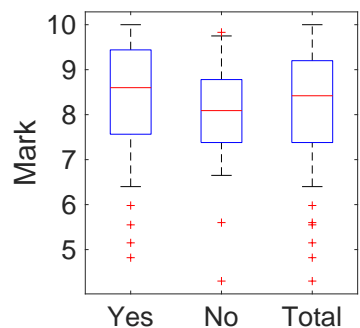

(c) $20 / 21$

Fig. 4. Whisker plot of marks, by differentiating between those students who have responded to the CHAEA survey, those who have not responded to the survey and all students (who have responded and who not) for subject TCIS.

pragmatist style depicted the worst results, followed by the activist. Regarding the grades, it can be checked that the best students are theoretical except for one of them, who have an equilibrium in the distribution of his capacities. There are two main groups of students, one of the over 5 points (grade) and the other below. The group who passed the subject is more theoretical and active, while the other is more reflexive and a bit pragmatic. Therefore, this subject evaluation model seemed to be more adequate for those students that do not need to participate actively in the lessons. TCIS presents very similar results for the four learning styles, being the theorist and the reflector those ones with less error. No clear trend is present in any style, although the best students obtained better marks in the theorist and reflector styles.

\section{Conclusions}

The utility of the learning styles resides in the knowledge that provides to both the teachers and students on improving the learning procedure. On one side, teachers would be able to have a better understanding of their students, and to adapt their methodologies to have more efficiency and save time. On the other hand, students can identify their profile, and use strategies to face the course more appropriately.

In this work, a study over three years has been elaborated to evaluate the relationship between learning styles and grades concerning two subjects of Computer Sciences Engineering. It was found that most of the students are theorists, and in second place, reflexive. Besides, the evolution over the years and different learning contexts do not reflect a big change in their predominant learning styles. The impact of the pandemic, and therefore the change of some teaching methods, did not affect the final marks of the students, which might indicate that the methodologies and evaluation were quite adapted to the audience.

Future works intend to analyze the evolution of learning styles and marks of the students on different degrees, not only in Computer Science, where dig- 

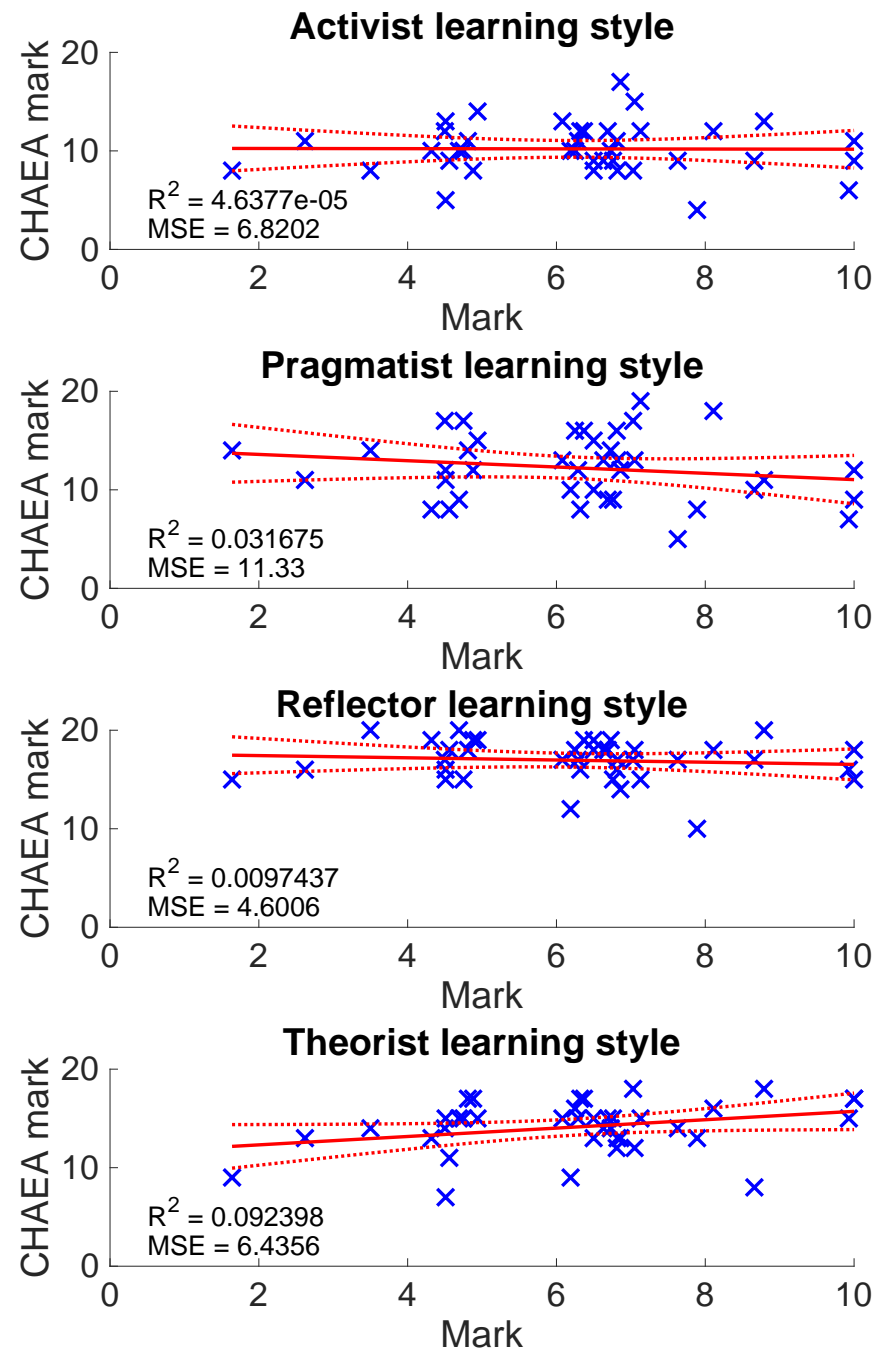

$\times$ Data — Fit …..... Confidence bounds

Fig. 5. For each learning style, the subject grades and the CHAEA marks of all participants have been analyzed with a linear regression model for subject TALF in the course $20 / 21$. 

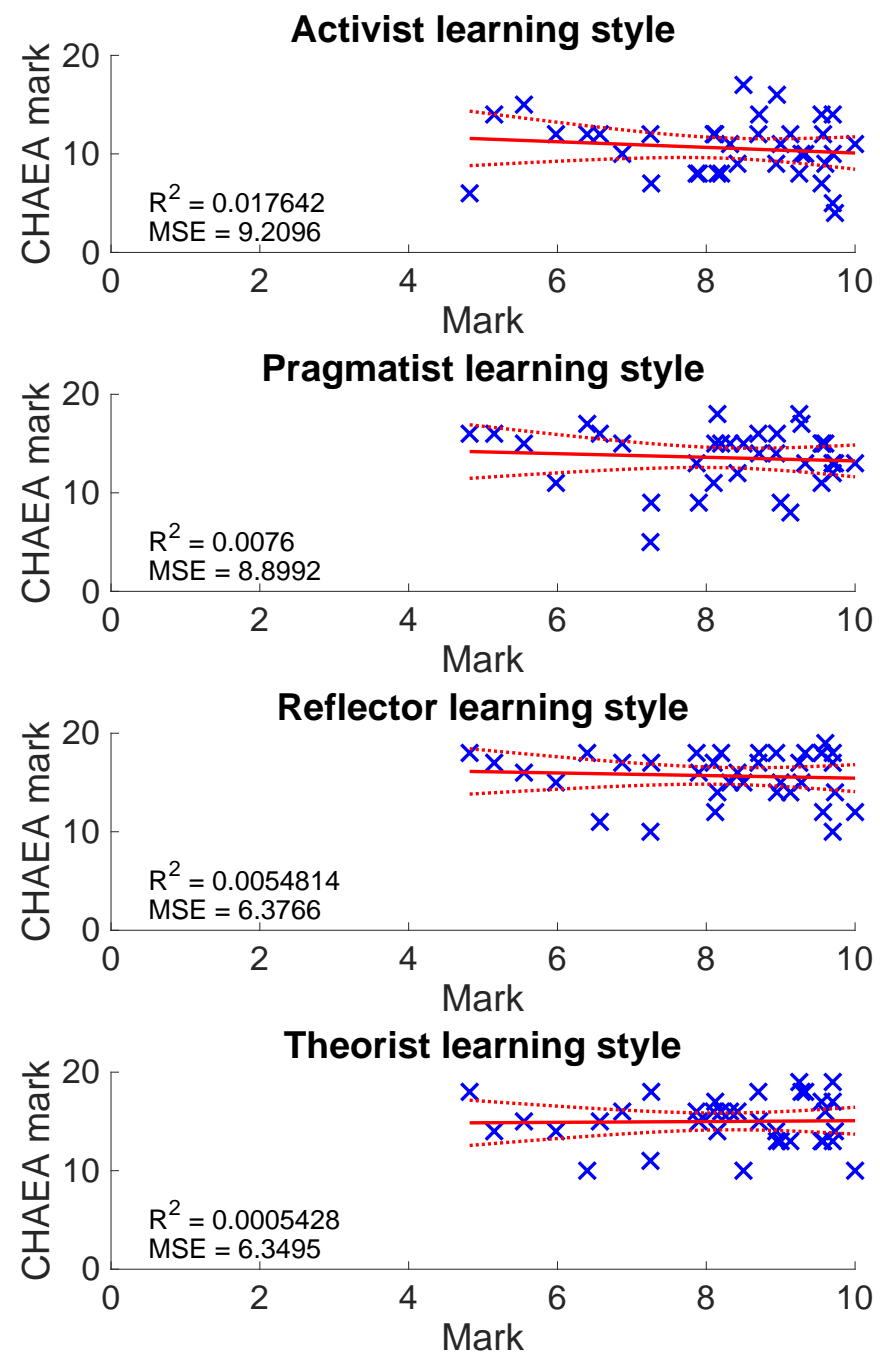

$\times$ Data — Fit …..... Confidence bounds

Fig. 6. For each learning style, the subject grades and the CHAEA marks of all participants have been analyzed with a linear regression model for subject TCIS in the course $20 / 21$. 
italization is intrinsic to the field. Actually, having more historic data would provide teachers a useful tool for designing better the whole academic course for a specific degree.

\section{Acknowledgments}

This work is partially supported by the University of Malaga (Spain) under grants PIE19-161, project name Cooperative Evaluation Procedures in Active Methodologies, and PIE19-219, project name Critical review of evaluation systems. The authors thankfully acknowledge the grant of the Universidad de Málaga, I Plan Propio Integral de Docencia.

\section{References}

1. Alonso, C.M., Gallego, D.J., Honey, P.: Los estilos de aprendizaje: procedimientos de diagnóstico y mejora. Mensajero Bilbao, España. (1997)

2. Escanero-Marcen, J., Soria, M., Guerra-Sánchez, M.: Estilos de aprendizaje y rendimiento académico: diferentes herramientas, diferentes resultados. Revista de la Fundación Educación Médica 21(4), 173 (2018)

3. Göğüs, A., Ertek, G.: A scoring approach for the assessment of study skills and learning styles. International Journal of Information and Education Technology 10(10), 715-722 (2020)

4. Honey, P., Mumford, A.: The Manual of Learning Styles. Peter Honey Maidenhead (1982)

5. Juarez Lugo, C.S., Rodriguez Hernandez, G., Luna Montijo, E.: The learning styles questionnaire CHAEA and the learning strategies scale ACRA as potential tools for academic tutoring. Journal of Learning Styles 5, 148-171 (2012)

6. Kolb, D.: Learning Style Inventory Technical Manual. McBer (1976)

7. Lai, S., Sun, B., Wu, F., Xiao, R.: Automatic personality identification using students' online learning behavior. IEEE Transactions on Learning Technologies 13(1), 26-37 (2020)

8. Marín, P.A.R., Herrán, A.O., Darío Duque Méndez, N.: Rules based system to educative personalized strategy recommendation according to the chaea test. In: 2016 XI Latin American Conference on Learning Objects and Technology (LACLO). pp. $1-7(2016)$

9. Mena Lorenzo, J.L., Rodriguez-Pulido, J., Mena Lorenzo, J.A., Navarro-Guzman, I, J., Silvio Cabrera-Guzman, J.: Learning styles of engineering students: development, performance and gender. European Journal of Edaction and Psychology 12, 175-189 (2019)

10. Rice, W.: Moodle E-Learning Course Development. Packt Publishing Limited (2015)

11. Santizo Rincon, J.A., Garcia Cue, J.L., Gallego, D.J.: Two methodes for the identification of differences between studies where the CHAEA has been applied. Journal of Learning Styles 1(1), 28-42 (2008)

12. Soflano, M., Connolly, T.M., Hainey, T.: Learning styles in adaptive games-based learning. In: International Joint Conference SOCO'13-CISIS'13-ICEUTE'13. pp. 709-717. Springer (2014)

13. Weinstein, C.E., Palmer, D.R., Acee, T.W.: LASSI User's Manual: For Those Administering the Learning and Study Strategies Inventory (3th ed.) (2016) 